\title{
Nursing education curriculum for improving patient safety
}

\author{
Mojtaba Vaismoradi \\ Faculty of Nursing \& Midwifery, Tehran University of Medical Sciences, I ran
}

Correspondences: Mojtaba Vaismoradi. Address: Faculty of Nursing \& Midwifery, Tehran University of Medical Sciences, Iran. Telephone: 98-918-316-0884 or 358-040-360-4382. Email: vaismoradi@razi.tums.ac.ir

Received: November 6, 2011

Accepted: November 14, $2011 \quad$ Published: February 1, 2012

DOI : 10.5430/jnep.v2n1p101

URL: http://dx.doi.org/10.5430/jnep.v2n1p101

\begin{abstract}
In preparing future nurses who are competent to provide safe care, nursing education has an important role in developing knowledge, skills, and attitudes of nurses. This article aims to present important points about the incorporation of patient safety into the nursing education curriculum for improving patient outcomes. It is concluded that policy makers and educators should attend the development of necessary competencies in nurses, bring creativity into the style of patient safety education, and consider the cultural specific aspects of the phenomenon of patient safety during designing nursing education curricula.
\end{abstract}

\section{Key words}

Curriculum, Nurses, Nursing education, Patient safety

Patient safety has become a major public health concern following the publication of the landmark report, To Err Is Human, by the Institute of Medicine in 1999. This report, along with a subsequent report, Crossing the Quality Chasm, recommended the design of a safer health care system by integrating well-established safety methods to avert medical errors. While these publications brought an ever-increasing attention to the issue of patient safety in practice settings, the international community of nurses has not converged to devise a global approach to patient safety.

The emphasis on the presence of safety risks in hospitals and their consequences on patients and their families have brought about an erosion of public trust as well as a tremendous economic and ethical burden on healthcare systems and healthcare providers ${ }^{[1-3]}$. In this regard, nurses have been recognized as crucial members of the quality care team, and their performances are integral to improving patient safety in the healthcare system ${ }^{[4]}$. Although the major focus on patient safety has been on implementing safe practices, it has become increasingly apparent that achieving a high level of safety in healthcare organizations requires much more ${ }^{[5]}$. Accordingly, the most common group of factors associated with patient safety issues are nurses' knowledge and its application in practice ${ }^{[6]}$.

Nurses are challenged to design the educational approaches so that nurses have the necessary skills to provide safe care ${ }^{[3]}$. Currently, patient safety is not taught to students as a separate topic, therefore after graduation, nursing students are not quite familiar with the phenomenon of patient safety and the role nurses have in improving the safety of services delivered to patients. It seems that because of a lack of knowledge, practice errors are considered a normal part of nursing practice and nurses are losing their sensitivity to the seriousness of errors. Additionally, in those nursing curricula that cover patient 
safety, the time devoted to the topic is modest ${ }^{[7]}$. Moreover, informing nurses of the implications of patient safety occurs after a nursing practice error has alerted healthcare policy makers about the intertwined identity of nursing quality care and patient safety. An approach which is preventive towards patient safety issues in the education of patient safety should be the preferred approach instead of waiting for an error to occur. Thus, the phenomenon of patient safety should be introduced to nursing students in their studentship period and continuously reminded during their work period in practice. A sweeping change in health care calls to transform nursing curricula in order to match the competencies of new graduates with practice needs ${ }^{[8,9]}$. For example, given global aging, a focus of an international patient safety curriculum should include the examination of the association between aging and medical errors as well as identifying geriatric syndromes as preventative medical errors. Teaching modules on the detection and reporting of geriatric syndromes, identifying system failures when geriatric syndromes occur, establishing dedicated geriatric units, improving the continuity of care, reducing adverse drug events, and improving geriatric training programs should be developed.

Nursing students often struggle in their practice after graduation. Perhaps, this is due to having been trained to practice in the workplace with the ideal condition in terms of the staffing pattern, leadership, facilities and equipment. This discontinuity in nursing education and practice ${ }^{[10]}$ calls for the development of creative ways to educate students so that the transition to practice is smooth. Nurse executives have a stake in assuring that new nurses are prepared with the competencies that will assure safe patient care, and nursing instructors have a stake in assuring that their graduates are prepared to contribute to the continuous improvement of the healthcare systems in which they work ${ }^{[8]}$.

As a main issue in nursing education, responsible faculties for the education of patient safety have not received similar education during their own studentship. For instance, they completed their own education prior to the emphasis on quality improvement processes, safety and error prevention techniques, and may not have received the same continuing education that practice settings have provided for nurses in practice ${ }^{[8]}$. Another significant challenge is that patient safety is still a relatively new concept and many educators are unfamiliar with how to integrate patient safety learning into the existing curriculum $^{[11]}$. It is suggested to employ clinical nurses who are receiving continuous practice updates to provide the clinical placement of nursing students in lieu of faculty members. Then faculty members can focus on teaching the theoretical aspects of patient safety. By using this method, the nursing education curriculum goes beyond theoretical concepts of patient safety education and increases the application of safety knowledge and competencies in nursing practice ${ }^{[12]}$. Nurse educators preparing the next generation of nurses must educate future nurses to understand micro and macro systems of the hospital environment. That knowledge will empower nurses in their roles that directly and indirectly affect patient safety ${ }^{[13]}$.

There should be a dynamic interaction between clinical practice and nursing education, in which the main causes of patient safety issues based on errors and near misses in practice are explored and used to give feedbacks to nursing education. It is a responsibility to alert nursing students to the realities of healthcare systems and to prepare them to practice with the competencies necessary ${ }^{[14]}$.

Nursing students should become familiar with the strategy of 'zero tolerance in practice errors'. As far as the physical and psychological consequences of nursing errors to patients may not be reconcilable, the importance of prevention from practice errors should be emphasized. Especially clinical instructors are in a very powerful position to help promote students' attitudinal development by making the impact of errors explicit and by relating them to nursing practice ${ }^{[15]}$.

There is also a need for a cultural shift in nursing education involving modifications in the process of teaching the content of patient safety, addressing discontinuity between education and practice and pursuit of patient safety improvement in clinical practice, and moving toward an international approach to the designation of nursing curriculum. Nurses need to have openness about errors and near misses, one in which, these are presented to the community of nurses and examined for strategies to prevent the error from occurring. Open multi-professional forums should be established where sharing occurs on a weekly time schedule to allow nurses to share near misses and then to strategize mechanism that are 
preventative. Such an approach will require the role modeling by instructors and then the support of such strategies in the healthcare system.

The primary cultural change recommended is in the style by which the principle of patient safety is transferred to nursing students. A wrong perspective is to think that only nurses are responsible for improving patient safety, but all healthcare professionals are responsible and a multi-professional approach is required to make the healthcare system safer. It is found that the happening of some nursing errors is secondary to other professionals practice errors ${ }^{[16]}$. In this regard, the modification should contain education about shared decision-making, and the facilitation of multidisciplinary communication and processes ${ }^{[8,14]}$. At the same time, students in other healthcare disciplines should be given lessons about patient safety and the necessity of collaboration with nurses to make health care safer. It is known that there is little dedicated teaching time for patient safety in the medical discipline. Above all, incorporation of patient safety teaching into clinical postings has been advocated, but this is limited by the lack of trained tutors ${ }^{[17]}$. Also, education typically occurs in isolation with few shared learning opportunities among the many health disciplines ${ }^{[18]}$.

It should be noted that enacting patient safety in clinical settings needs something more than laws or acts and even the legislative support. The point is that patient safety should be actively internalized by nursing students as a patient right and humanistic value in nursing practice ${ }^{[12,19]}$.

The designation of an international and multi-professional patient safety curriculum and its prescription to the disciplines of healthcare may bring unity to healthcare systems globally. However, the availability of a universal patient safety curriculum should provide nursing schools with an opportunity to adapt culturally specific issues into their own patient safety curriculum ${ }^{[11]}$. In other words, cultural and contextual factors should be incorporated into patient safety curricula. For instance, there are healthcare systems that have no mechanism to track errors, and it is only through nurses' self-identification can lessons be learned by the entire team of providers. However, at the core is the ethical responsibility of safe practice regardless of international location ${ }^{[20]}$.

Infection control, safe use of medicines, equipment safety, safe environment of care and prevention from patient falls, protection against environmental hazards, and the subjective feeling of safety in patients are aspects of patient safety, which should be included during designing an international patient safety curriculum. However, patient safety has predominately been introduced as medication error with a lack of the numerous parts of the phenomenon of patient safety and their impacts on quality care ${ }^{[21]}$. It may be related to the publicized consequences of medication errors, which have hidden the identity of other parts of patient safety. Patient safety knowledge requires additional learning that is more wholistic in nature ${ }^{[10,11]}$. The discipline of nursing is required to make nursing students familiar with the phenomenon of patient safety as a whole and provide them with valid and reliable tools to receive feedback about the level of patient safety and the consequence of endangering patient safety from both physical and psychological aspects ${ }^{[9,15]}$.

\section{Conclusion}

The improvement of patient safety in the healthcare system depends on knowledgeable nurses who have been taught and trained based on a well-established and sound nursing curriculum. In the process of devising strategies to improve patient safety or designing the nursing education curriculum, policy makers and educators should attend the development of necessary competencies in nurses, bring creativity into the style of patient safety education, consider the different aspects of the phenomenon of patient safety, and incorporate cultural aspects into the educational curriculum. Moreover, future studies can help nurse educators facilitate the process of the transfer of patient safety knowledge into practice.

\section{Acknowledgements}

This letter has been written during scholarly visits to University of Eastern Finland and University of Nordland in Norway. The author would like to sincerely thank Prof. Hannele Turunen and Prof. Terese Bondas for their precious supervision and teaching during the visits. 


\section{Conflict of interest}

No conflict of interest has been declared by the author.

\section{References}

[1] Warburton R. Improving patient safety: an economic perspective on the role of nurses. J Nurs Manag. 2009; 17: 223-9. PMid:19416426 http://dx.doi.org/10.1111/j.1365-2834.2009.00992.x

[2] Reid J, Catchpole K. Patient safety: a core value of nursing - so why is achieving it so difficult? J Res Nurs. 2011; 16: 209-223. http://dx.doi.org/10.1177/1744987110393454

[3] Sherwood G. Integrating quality and safety science in nursing education and practice. J Res Nurs. 2011; 16: $226-240$. http://dx.doi.org/10.1177/1744987111400960

[4] Kohlbrenner J, Whitelaw G, Cannaday D. Nurses critical to quality, safety, and now financial performance. J Nurs Adm. 2011; 41: 122-128. PMid:21336040 http://dx.doi.org/10.1097/NNA.0b013e31820c71f9

[5] Leape LL. Errors in medicine. Clin Chim Acta. 2009; 404: 2-5. PMid:19302989 http://dx.doi.org/10.1016/j.cca.2009.03.020

[6] Ball MJ, Douglas JV. Redefining and improving patient safety. Methods Inf Med. 2009; 48: 271-276.

[7] Maeda S, Kamishiraki E, Starkey J, Ehara K. Patient safety education at Japanese nursing schools: results of a nationwide survey. BMC Res Notes. 2011; 4: 1-33. PMid:22005273 http://dx.doi.org/10.1186/1756-0500-4-416

[8] Sherwood G, Drenkard K. Quality and safety curricula in nursing education: Matching practice realities. Nurs Outlook. 2007; 55: 151-155. PMid:17524803 http://dx.doi.org/10.1016/j.outlook.2007.02.004

[9] Okuyama A, Martowirono K, Bijnen B. Assessing the patient safety competencies of healthcare professionals: a systematic review. BMJ Qual Saf. 2011; 20: 991-1000 http://dx.doi.org/10.1136/bmjqs-2011-000148

[10] Gregory DM, Guse LW, Dick DD, Russell CK. Patient safety: where is nursing education? J Nurs Educ. 2007 ; 46: 79-82. PMid:17315567

[11] Walton M, Woodward H, Van Staalduinen S, Lemer C, Greaves F, Noble D, Ellis B, et al. The WHO patient safety curriculum guide for medical schools. Qual Saf Health Care. 2010; 19: 542-546. PMid:21127112 http://dx.doi.org/10.1136/qshc.2009.036970

[12] Vaismoradi M, Salsali M, Marck P. Patient safety: nursing students’ perspectives and the role of nursing education to provide safe care. Int Nurs Rev. 2011; 58:434-442. PMid:22092321 http://dx.doi.org/10.1111/j.1466-7657.2011.00882.x

[13] Bloch JR. Patient safety and nursing education. J Nurs Scholarsh. 2005; 37: 97. http://dx.doi.org/10.1111/j.1547-5069.2005.00019_1.x

[14] Neudorf K, Dyck N, Scott D, Davidson D. Nursing education: A catalyst for the patient safety movement. Healthc Q. 2008; 11: 35-39. PMid:18382159

[15] Glavin R. What every clinical teacher should know about patient safety. Clin Teach. 2006; 3: 103-106. http://dx.doi.org/10.1111/j.1743-498X.2006.00082.x

[16] Vaismoradi M, Salsali M, Ahmadi F. Nurses' experiences of uncertainty in clinical practice: a descriptive study. J Adv Nurs. 2011; 67: 991-999. PMid:21214617 http://dx.doi.org/10.1111/j.1365-2648.2010.05547.x

[17] Thain S, Bee-Leng Ang S, Ti Lk. Medical students’ preferred style of learning patient safety. BMJ Qual Saf. $2011 ; 20: 201$. http://dx.doi.org/10.1136/bmjqs.2009.039198

[18] Sherwood G. New views of quality and safety offer new roles for nurses and midwives Nurs Health Sci. 2010; 12: $281-283$. http://dx.doi.org/10.1111/j.1442-2018.2010.00539.x

[19] Dudas RA, Bundy DG, Miller MR, Barone M. Can teaching medical students to investigate medication errors change their attitudes towards patient safety? BMJ Qual Saf. 2011; 20: 319-325. http://dx.doi.org/10.1136/bmjqs.2010.041376

[20] Vaismoradi M, Salsali M, Turunen H, Bondas T. Patients' understandings and feelings of safety during hospitalization in Iran: A qualitative study. Nurs Health Sci. 2011; 13:404-411. http://dx. doi.org/ 10.1111/j.1442-2018.2011.00632.x

[21] Vaismoradi M. Patient safety is not just about medication errors. Int Nurs Rev. 2011; 58: 286. PMid:21848771 http://dx.doi.org/10.1111/j.1466-7657.2011.00937.x 